\title{
Sick building syndrome: A review of causes, consequences and remedies
}

Received (in revised form): 26 October 2008

\section{Jack Rostron}

is a solicitor, chartered surveyor and chartered town planner, who researches the needs of the physically disabled in the built environment. He is the author of several papers and books and sometime adviser to the World Health Organization.

\begin{abstract}
This paper aims to discuss the causes, consequences and means of ameliorating sick building syndrome (SBS). The approach adopted is to review and analyse the potential causes of SBS in terms of heating and ventilation systems, temperature, indoor air pollutants, noise, lighting, hygrothermal factors and psychological factors. The results of the review show the consequences of SBS in terms of the range of medical symptoms exhibited, personnel/human resources issues and economic consequences. The benefit of the paper is that it offers a means of eliminating and/or reducing the consequences of SBS in terms of architectural design, mechanical engineering design, maintenance policies and management techniques.
\end{abstract}

\section{Keywords:}

sick building syndrome, architectural design, mechanical engineering, maintenance management

Journal of Retail and Leisure Property (2008) 7, 291-303. doi:10.1057/rlp.2008.20; published online 1 October 2008

\section{INTRODUCTION}

Sick building syndrome (SBS) is recognised by the World Health Organization as 'a syndrome of complaints covering nonspecific feelings of malaise, the onset of which is associated with occupancy of certain modern buildings' (Wilson and Hedge, 1987). A syndrome is defined as 'a collection of signs and symptoms fitting a recognisable pattern' (World Health Organization, 1983). Symptoms characterising SBS are commonplace in the general population, but it is the pattern of their expression that points to the diagnosis of SBS.

Here it is important to note that some authors (and studies) speak of

Jack Rostron

Liverpool John Moores University Peter Joste Centre

Byrom Street

Liverpool, L3 3AF, UK

Tel: +44 (0)1512312856

Fax: +44 (o)1512312815

E-mail: j.rostron@ljmu.ac.uk building-related illnesses (BRI). Goldman (1996) also differentiates between SBS and BRI. Here, SBS is where the occupants of a building are affected over an indefinite period, and is directly connected with the building itself. BRI, however, refers to a pathological condition, harmful not only to the regular, everyday occupants, but also to visitors and 
passers-by. Goldman (1996) also believes that the symptoms characterising SBS, first noted in the 1950s, appeared to be correlated with the development of post-war, energy efficient, airtight buildings, at a time when the architects' main brief was to keep costs low. BRI includes sicknesses such as Legionnaires disease, which may be contracted as a direct result of entering a building, but continues to have an effect after the sufferer has vacated the building (MacNeil, 1995).

Although variations of the words used to characterise the phenomenon do exist, there is clear consistency in the way in which the syndrome is being described. We will hereon accept SBS to be a phenomenon whereby people experience a range of symptoms after a few hours of leaving the building, yet are relieved of these symptoms after a few more hours(Raw, 1992). The term SBS should be restricted to multi-factorial problems, where no single cause factor exceeds the level of generally accepted recommendations (Potter, 1988; Hewitt, 2007).

\section{SYMPTOMS}

The symptoms of SBS have over the years been fairly well established. A study by Molhave (1987) (cited Potter, 1988) concluded with a refined list of five 'symptoms criteria':

- Sensoric irritation in eyes, nose or throat

- Dryness.

- Stinging, smarting, irritating sensation.

- Hoarseness, changed voice.

- Skin irritation

— Reddening of skin.

- Stinging, smarting, itching sensation.

- Dry skin.

- Neurotoxic symptoms

- Mental fatigue.

- Reduced memory.

- Lethargy, drowsiness.

- Reduced power of concentration.

- Headache.

- Dizziness, intoxication.

- Nausea.

- Tiredness.

- Unspecified hyperactions

- Runny nose and eyes.

- Asthma-like symptoms in nonasthmatic persons.

- Respiratory sounds.

- Odour and taste complaints

— Changed sensitivity.

- Unpleasant odour or taste.

Molhave (1987) stipulates that sensoric irritation must be one of the dominating complaints, and also stresses that systemic symptoms, for example complaints arising from problems in the lower airways or the 
stomach, should not be a dominant complaint, and there should be no identifiable single cause in relation to the problem.

Raw (1992) suggests that taste and odour anomalies are not necessarily symptoms. It is most probable that they are environmental perceptions unique to individuals and therefore are best excluded from the list of symptoms. Likewise, breathing difficulties should be treated with the same caution (people could be identified with asthma rather than SBS).

Some investigators have produced more extensive lists of symptoms, including (among others) airway infection, coughs, wheezing, nausea, dizziness and high blood pressure. Also to note is that the range and prevalence of the symptoms reported may be directly related to the number and the nature of the questions used in the research process. Also, the use of different frequency scales used to report the frequency of symptoms and discomfort may distort and/or manipulate the findings (Raw et al., 1994).

The general nature of the symptoms means that they will be reported to some degree in all buildings. It is found, however, that the level of symptoms varies between buildings, and buildings where symptom rates were high do tend to have a number of common features - as mentioned previously (Goldman, 1996).

\section{THE IMPLICATIONS OF SBS}

Some may argue that the symptoms of SBS could easily be regarded as minor as there have been no reports of any lasting physical damage with symptoms normally disappearing rapidly after the affected person leaves the affected building. These symptoms are not minor to those affected in their place of work, however.

SBS can have serious wider implications: reduced productivity: many sufferers have reported that their productivity levels have been reduced by up to 20 per cent (Tong, 1991); reduced overtime; and increased staff turnover: the population of office workers is a volatile one with workers regularly changing jobs, as opposed to dedicating their career to one company. It is likely that office conditions are slowly beginning to influence the decisions of workers when considering a change increased sickness and therefore absenteeism. Private litigation against employers by workers who have become ill as a consequence of foul air has resulted in substantial financial settlements.

Some buildings affected may require costly and dramatic remedial work, that is, replacement of air-conditioning systems, windows and furnishings. For some buildings, however, demolition may prove to be the only, or the most economic, action. The Inland Revenue gave up on its 19-storey building in Bootle, Merseyside in 1995 after intolerable levels of staff absenteeism, with a reported half of the 2000-strong staff, over the previous five years, suffering from SBS symptoms (Goldman, 1996).

Therefore, it is clear to see that the cost of reduced productivity, replacement staff and litigation make prevention unarguably better than cure. 


\section{POSSIBLE CAUSES OF SBS}

Much research has been carried out to try and establish conclusively the cause(s) of SBS. Unfortunately, this has not yet been achieved (White, 1993; Staus, 2004). The pattern of occurrence of the symptoms - that is, during the working day and week - rules out the possibility of the problem being that of an infection. It is important to understand that a consideration of the physical environment should also be given attention. In all probability there is a different combination of causes in different buildings (Morris and Dennis, 1995).

Many possible causes of SBS have been suggested, with the majority of explanations focusing on air quality within the building and the systems that are used to ventilate the building. Other factors that have been implicated are noise, artificial lighting, control by occupants, cleaning of the workplace, stress and psychological effects (among others).

\section{HEATING AND VENTILATION SYSTEMS, AND THERMAL COMFORT}

Mechanical ventilation of buildings differs from natural ventilation in a number of ways:

- With natural ventilation, occupiers have a choice of opening/closing windows. This is not the case in mechanically sealed buildings.

- Any mechanical system is subject to design fault and poor installation. Components may fail and have a devastating impact on the systems' performance.

- Ventilation systems can harbour organic growth, and may distribute contaminants from one area throughout the building.

Evidence for a correlation between ventilation rate and SBS symptoms is at best patchy. Generally, air-conditioned buildings have higher rates of symptoms than naturally ventilated buildings.

There are many reasons why ventilation may be inadequate in buildings: malfunctioning ventilation systems, badly maintained systems, badly designed or ill-controlled systems or inadequate distribution of air within the space.

Even if appropriate volumes of fresh air are delivered to a space, it may not reach the occupants in the way intended. Distribution is susceptible to problems caused by changes in layout of office spaces and to unregulated covering of air inlets by building occupants.

Probably the most crucial aspect of ventilation is the practice of maintenance of ventilation systems.

Fresh air is required in air-conditioning systems to supply air for respiration and to dilute carbon dioxide and other contaminants. Ventilation is required to maintain personal comfort. Standards have been set for ventilation and fresh air rates, usually based on the air required to dilute body odours.

\section{TEMPERATURE}

There is fairly strong evidence that there is a correlation between temperatures at and above $23^{\circ} \mathrm{C}$ and the prevalence of symptoms. Therefore, it should be limited to $22^{\circ} \mathrm{C}$ during winter heating. 


\section{INDOOR AIR POLLUTANTS}

The subject of indoor air quality (IAQ) is far too in-depth to be covered in detail here and therefore a brief discussion of IAP will be given.

Within buildings there are many sources of pollution, including the occupants, the buildings and furnishings, office materials and equipment, building services and the environment outside the building. Consequently, there is a wide range of pollutants in the indoor environment. Owing to the low levels of each pollutant found, it has proved very difficult to show clear differences between 'sick' and so-called 'healthy' buildings with respect to levels of pollutants.

Inorganic gases such as carbon dioxide and ozone may occasionally create problems, but they are not thought to be widespread causes of SBS. Sense of smell is an unreliable indicator of some of the most dangerous contaminants (Rowe, 1994).

Volatile organic chemicals (VOCs), for example formaldehyde, are released by a large number of materials and processes in buildings and by the occupants, often reaching moderately high levels.

Few studies have analysed the role of VOCs in SBS in a controlled way and therefore the measurement and effects of a mixture of VOCs are not sufficiently or clearly understood. It is thought, however, that the levels of VOCs will be significantly higher in new buildings than in older buildings.

SBS has been shown to be related to the size of areas in which dust and air can collect in the building, which provide breeding sites for microorganisms and the like. Microorganisms are more likely to be present in older buildings than in newer buildings.

Studies have shown that airborne dust levels are a significant factor. Dust cannot be regarded as simply an air pollutant, effective only when inhaled, since it can be transferred direct to the skin or ingested with food/drink.

It is clear that there are many combinations of sources of pollutants, and in addition, the sources may not be independent. The potential range of pollutants in the office environment is therefore enormous.

\section{NOISE AND SPEECH PRIVACY}

Noise transmission and speech privacy are complex topics. Noise can contribute to SBS, but in differing ways. Whether or not the noise level is disturbing or annoying to an occupant depends on numerous factors, psychological and physiological, which vary from person to person (Potter, 1988).

Traffic or external noise is not usually considered to be a problem in air-conditioned buildings with sealed windows. But in older buildings that rely on opening windows for ventilation, external noise can be a cause of serious inference. If this is the case, it can only be prevented by careful placement of openings, to try and prevent direct transmission pathways.

Sometimes low noise emission is acceptable and may even be useful to help dampen the general noise level in open planned offices.

Nevertheless, there are occasions when unacceptable levels of intrusive noise occur in occupied spaces. If necessary, a suitable contaminant or 
hearing protection partition should be provided. If the problem is that of low frequency noise from office equipment, this could be 'deadened' by introducing a level of background noise into the office (Rowe, 1994; Rostron, 1997). Through careful design, that is, rerouting of services and treatment, forms of intrusive noise can be avoided.

\section{LIGHTING/TINTED GLAZING}

The subject of lighting is an extremely detailed topic and ideally should be spoken about in-depth. The aim of this section is, however, to simply make the reader aware of the potential problem, and nothing more.

Lighting has the potential to affect health and comfort. Visual environments that fall outside the generally accepted design recommendations (eg those given in the Chartered Institution of Building Services Engineering (1994) Code for Interior Lighting) are those most likely to lead to unsatisfactory conditions.

Lighting is related to both general satisfactions in the indoor environment and the comfort of visual performance. Eye work under inappropriate lighting can be a very obvious cause of SBS, producing eye discomfort, eyestrain and fatigue.

The interior lighting of a building has three main purposes:

- To enable occupants to work and move about safely.

- To enable tasks to be performed properly.

- To enhance appearance.

The main aspects of lighting that have been attributed to SBS are the provision of daylight and the quality of artificial lighting provided in the workplace. Many existing buildings have been designed with a simple approach based on illumination levels.

The basic quantity of illumination required for performing tasks depends largely on the age and eyesight of workers, as well as on the task being carried out.

Lighting has to be designed for most office situations reasonably early in the overall process, to fulfil contractual and installation obligations. The values of reflectances are agreed upon with the architect at this early stage. The final decision on finishes very often takes place much nearer the completion of the project and therefore there is a higher probability that reflectances will differ greatly from those used in the lighting calculations. It is not clear as to whether or not colour finishes contribute directly to SBS.

Repeated dilation and contraction of the pupils of the eyes can bring about eye irritation. This can result from repeated adaptation to variations in brightness of adjacent parts of the field of view. A change of the tone or colour of wall surfaces to reduce the variation is the simplest remedy.

There appears to be a correlation between tinted windows and a higher incidence of symptoms. It is possible that this is because of a direct link between tinted windows and a particular generation of buildings. 
People seated near windows tend to have fewer symptoms, although no reason for this has yet been established; possibly it is psychological.

\section{HYGROTHERMAL FACTORS}

Hygrothermal factors include temperature, humidity and air movement, all of which have an effect on the comfort of building occupants. The complex way in which these factors interact to produce feelings of thermal comfort and dryness may be responsible for some of the complaints of SBS.

Temperature, humidity and air movement must be considered as determinants of IAQ because they affect not only comfort, but also the rate of emissions and depositions of pollutants from materials in the buildings and from people.

Although various standards have been set for optimum comfort, in reality, no single thermal environment is ideal for everyone and even if conditions are 'ideal' there will still be a percentage of occupants who will be dissatisfied.

Dissatisfaction with the thermal environment is often greater in larger air-conditioning buildings than in smaller, naturally ventilated buildings. In naturally ventilated buildings, the occupants are able to open windows and control radiators and therefore are able to vary, to some extent, the thermal environment. In air-conditioned buildings, however, the buildings are generally 'tight' and there is little that the occupant can do to improve conditions.

To conclude on hygrothermal factors, it is clear that little is known about the effects of fluctuations in the thermal environment. Large and slow fluctuations reduce thermal comfort, while small, rapid fluctuations decrease worker productivity and cause sleepiness and fatigue. A constant thermal environment seems to be preferable to either type of fluctuation.

\section{DESIGN OF BUILDING SERVICES}

The traditional route for the design of building services is as follows:

- Client informs architect of requirements.

- Architect produces outline sketches.

- Outline sketches passed to structural engineer who carries out structural design.

- Architect passes both sets of drawings to the service engineer.

Some would argue that a more appropriate route would be to gather all designers together at the earliest possible opportunity to discuss all aspects of the building (Kanuka-Fuchs, 2001). In this way, the service engineer can design the services parallel to the design of the building shell. If services are designed in isolation, there is no knowing how they will behave within the building as a whole unit.

Elements such as heating, ventilation and lighting should be designed so as not to impair one another's effective operation. 


\section{CONSTRUCTION PRACTICE}

The installation of systems (especially air-conditioning systems) must be carried out in such a manner as to ensure that the system is not susceptible to breakdown, that it is clean to begin with and that it is easy to maintain.

\section{SPECIALIST CLEANING}

High levels of cleanliness should be specified to prevent SBS. With regard to air-conditioning, ductwork shall be cleaned after installation by a specialist-cleaning contractor. There should be adequate access to allow cleaning of the installation to be undertaken thoroughly.

\section{INDUSTRIAL CLEANING OF THE WORKPLACE}

Cleaning and maintenance are two of the most important factors influencing SBS (Rideout, 1995). Regular cleaning and maintenance of items such as air-conditioning, building fabrics and lighting creates a sense of wellbeing among employees, indicating to them that they are appreciated by the company's management in that he/she is concerned enough to create a pleasant working environment.

An untidy workplace is hazardous and looks unprofessional. It has been estimated that if workplaces were kept as clean as domestic dwellings, the number of accidents that occur could be halved.

It is often the case that janitorial services for office buildings are near the bottom of the list of priorities. A survey carried out by Dyna-Rod (cited Rostron, 1997) concluded that a majority of building owners carry out crisis maintenance - that is, wait for the system to fail before carrying out repairs.

Industrial cleaning is a specialised industry involving trained staff with specialist equipment and detergents. By using such specialists, there may be a reduction in the symptoms of SBS if pollutants are believed to be the main cause, or even a contributory cause, of SBS.

\section{PERSONAL ENVIRONMENTS SYSTEMS}

Personal environments systems (PES) is a system of individual environmental control for open plan offices. Each workstation within the office has access to facilities - electricity, telecommunications, data communications and conditioned air. Individuals are able to adjust the system to meet their own needs.

The personal environment module (PEM), which acts as the control centre, is mounted beneath the work surface of open plan office furniture. It enables the occupant to have control over the following:

- air flow/speed,

- heat/temperature,

- background noise,

- light.

An infrared sensor in the control panel automatically turns the PEM off or on when the station is unoccupied or occupied, respectively. 
If we assume that personal temperature, lighting preference, noise preference, etc differ from person to person, it would be impossible to design a HVAC system to suit all needs. Therefore, the possible use of PEMs may be one way to eradicate SBS from the workplace.

If the occupant is more content with their working environment, then they are more likely to stay at their desks for longer periods of time and therefore increase productivity levels.

\section{TYPE OF JOB}

Job stress and dissatisfaction are probably more important causes of symptoms than physical and chemical factors in the indoor environment.

The prevalence of symptoms appears to be highest among clerical staff, with their more routine work, than among professional staff. When concentration strays, it is likely that a greater examination of the environment may take place, and therefore clerical staff will be far more aware of minor changes in the working environment, especially if inactive for long periods of time. Those with more interesting, involving jobs and more control over their environment report significantly fewer symptoms (Building Use Studies, 1988; Health and Safety Executive, 1995).

The proportion of work time spent in front of computers is very important when considering the number of eye symptoms and satisfaction with lighting conditions. Very often computers are thought to be the cause of the problem when it is not the actual computers themselves that are the problem but rather the work carried out on them that causes the problems.

Recent studies indicate that the degree to which workers feel integrated into their organisation also affects the occurrence of symptoms (Jones, 1995; May, 2006).

\section{MANAGEMENT}

Having looked at nonhuman factors in relative detail, we come to the last issue of management as a possible contributing factor to the problem of SBS.

Leaman (1989), managing director of 'Building Use Studies', believes that SBS is not a sickness, but more an imbalance between management and building design. He further believes that incidences of SBS could almost be used as a negative indicator of how well organised a company is. Leaman emphasises that many larger corporate companies, which are naturally better organised, never suffer from SBS, even if they are potentially high-risk buildings.

It is important for management to show that they recognise environmental problems where they do exist, and it is also important for them to react in an appropriate manner. Staff with no environmental control will have their frustration and sense of helplessness worsened if they are confronted by a manager who refuses to acknowledge the importance of their complaint (Rowe, 1994).

Psychologically, it is far better to have investigated the complaints and communicated the reasons why action cannot be carried out than to have ignored the complaint altogether. Management attitudes are a prime 
influencing factor. According to Besch and Besch (1989) (cited in Raw, 1992), if problems are not dealt with rapidly and effectively, staff can lose confidence in management and become frustrated and despondent about their environment.

The subject of management factors contributing to SBS has two lines of thought:

1. Poor quality management can lead to inadequate environmental conditions that are a direct cause of SBS symptoms.

2. Poor quality management affects the sensitivity of staff so that they suffer or report symptoms even in environmental conditions that would otherwise be considered adequate.

People seem to be more sensitive to their environment and report higher levels of symptoms at times when there are management or organisational changes, and therefore communication between all levels is of vital importance.

To claim that bad management causes SBS can be seen either as claiming an obvious truth or as unfair nonsense (Raw, 1992). The true balance between these two views can only be reached by establishing specifically what management could have done to avoid the problem.

Taking a wider view, management could be seen as contributing to SBS if it does not do all that is possible to create a good indoor environment to avoid symptoms and stress. One symptom that could be avoided by improved management is the perception of lack of control over personal environment.

To conclude, management does have the potential to influence the occurrence of SBS in both a direct and an indirect way. Nevertheless, it is difficult to scientifically prove an association between the two (management and SBS).

\section{PSYCHOLOGICAL ISSUES}

One reason for the lack of an accurate cause or 'cure' for SBS is that the majority of investigations into SBS only look at part of the problem. If the problem were purely physical, a solution would have been found to eradicate the problem, so it is logical to reason that SBS is not purely a physical problem. Therefore, is there an element of psychology, such as job satisfaction, lack of local control and work-related stress attributed to the problem of SBS, and is the problem therefore far more complex than originally postulated?

For an accurate diagnosis of work-related illnesses, the investigation must include a thorough industrial hygiene examination that documents levels of pollutants in the air; building characteristics; the working environment; job demands and work-related stress; social support; perceived environmental control; and management issues.

Other important factors include the attitudes and belief systems of the individuals concerned, certain personality and behaviour patterns, and the presence of current stress or pre-existing psychological distress. The workers' perceptions of the competence and credibility of managers and 
professionals, and the influence and involvement of the media, pressure groups and the legal system, will all have an impact (Spurgeon, 1997).

One major need, of individual workers, is the need for control of their personal working environment. The need for control is closely associated with the need to be independent of the controls and restrictions of others, and to be able to manage one's own actions. When this freedom of control is lost, people react by reasserting their freedom, and display symptoms of SBS - 'psychological reactance'.

Continued loss of control is likely to result in 'learned helplessness' that is, continual expression of SBS symptoms. The effects of 'learned helplessness' are not easily changed, but with persistent positive reinforcement the association can be changed to a positive behaviour or reaction.

Building occupants generally accept that they have no control over their working environments. Working environments are usually set at appropriate levels (temperature, lighting, desk height, etc) before the users' arrivals into the building. If the occupant suffering from SBSrelated symptoms does make some attempt to question the working environment and this request is ignored, it is likely that the symptoms will become exaggerated - resulting in increased levels of absenteeism, which in turn results in reduction of the organisations productivity level.

Dr Wyon (cited Rostron, 1997) identified that the use of individual environmental control systems can increase productivity by up to seven per cent, and therefore also reduce absenteeism. Building occupants will feel in control of their working environment, and therefore become less susceptible to displaying SBS symptoms.

Over the past eight to ten years, there has been a change in the current business environment. Where organisational changes create uncertainty, resistance to change is likely to be evident. Seemingly, this resistance is not so much a resistance to change, but a resistance to the personal loss that is believed to accompany the change. This resistance will probably manifest itself, in some cases, as psychological reactance.

\section{CONCLUSION}

There is evidence that, although SBS does not cause serious damage to health, it does result in potentially problematic consequences. Apart from being distressing to the people experiencing the symptoms, SBS does cause widespread loss of productivity, increases sickness absence and takes up valuable time in making complaints and dealing with those complaints. If a building acquires a reputation for being 'sick', it can prove to be difficult to rehabilitate its reputation, even if it is clear that the building itself has been improved (Tong, 1991; Goldman, 1996). Extreme cases may lead to building closure or even demolition.

Employees who drag themselves into an unpleasant and disliked workplace everyday will not do much for productivity. If workers believe that the office environment affects their productivity, that belief is important whether it is correct or not. The belief itself may affect productivity, or the worker may leave for a job that offers a betterperceived environment. Dressel and Francis (1987) (cited Raw, 1992) 
found that improvements in the office environment have resulted in higher productivity.

If unhealthy environmental conditions persist, or remain unsolved, often the employees want to leave and go to a healthier working environment. Because different organisations and industrial sectors may have differing turnover rates, the question of whether this has reached the level of a serious problem depends on how the suspected 'sick' building compares with the average turnover rates for that type of industry.

The national population of office workers is becoming increasingly mobile. Professional office workers do expect, in this day and age, to move from job to job rather than spend their career in one company. As workers go from job to job, and office to office, it is possibly that office conditions are beginning to influence these moves.

The increasingly attractive working from home trend means that organisations will have to improve standards in office accommodation so that they are of a similar standard to those found at home.

Along with the three major potential problems - reduced productivity, increased absenteeism and increased turnover - there are other potential spin-offs.

Private litigation against employees by unhealthy working environments has resulted in punitive financial settlements.

Government legislation — both UK and Economic Union Legislation clearly lays down the necessity to monitor the working environment, especially with respect to air-conditioning systems, with potentially serious consequences for nonconformists.

Serious health risks - The toxic effects of poor IAQ can cause a myriad of allergies and infections.

\section{References}

Building Use Studies (1988). Sick office-off sick. Building. 21(4), 66-67.

Chartered Institution of Building Services Engineering (1994). Code of Interior Lighting, CIBSE, London.

Goldman, L. (1996). How sick is your building. Utilities L Review. 12(3), 14-15.

Health and Safety Executive (1995). Sick building syndrome in perspective. Architects Journal. 201(23), 41

Hewitt, J. (2007). Sick Building Syndrome, Lulu Books, USA.

Jones, P. (1995). Health and comfort in offices. Architects Journal. 201(23), 33.

Kanuka-Fuchs, R. (2001). Healthy Home and Healthy Office, Sick Building Syndrome, Indoor Pollution and Solutions, Beekman Books Inc., USA.

Leaman, A. (1989). Syndrome symptoms. Building. 22(2), 6.

MacNeil, J. (1995). Place Ache. Building. 28(19), 48-49.

May, J.C. (2006). My Office is Killing Me, John Hopkins University Press, USA.

Molhave, L. (1987). The sick buildings: A sub-population among the problem buildings. Proceedings of the 4th International Conference on Indoor Quality and Climate, West Berlin, Institute for Water, Soil and Air Hygiene, Indoor Air 1987 Vol. 2, 17-21 August 1987, pp. $469-473$.

Morris, A. \& Dennis, P. (1995). Survey findings of libraries in Great Britain. Library Management. 16(3), 18-22.

Potter, I.N. (1988). BSRIA.Technical Note 4/88.

Raw, G.J. (1992). SBS: A review of the evidence on causes and solutions. HSE Contract Research Report, No. 42/1992.

Raw, G.J. \& Tong, D. (1994). Questionnaire design for SBS Part 2: The effect of symptom list and frequency scale. Building Research Establishment, August 1995, pp. 16-17. 
Rideout, G. (1995). Itching to go home. Building Services. 260, 7897(25), Supplement 1995, pp. 22-24.

Rostron, J. (1997). SBS: Concepts, Issues and Practice, E \& FN Spon, London.

Rowe, D.M. (1994). Sick building syndrome: The mystery and the reality. Architectural Science Review. 37(3), 137-147.

Spurgeon, A. (1997). Non-specific exposure in the workplaceInstitute of Occupational Health, University of Birmingham.

Staus, D.C. (2004). Sick Building Syndrome, Academic Press, USA.

Tong, D. (1997). "Sick Buildings" what are they and what is their cause. Facilities. 9(7), 9-17.

White, P. (1993). Sick building syndrome awareness. Chartered Surveyors Weekly. 43(12), 9-11.

Wilson, S. \& Hedge, H. (1987). The Office Environment Survey: A Study of Building Sickness, Building Use Studies Ltd, London.

World Health Organization (1983). Indoor air pollutants: Exposure and health effects. World Health Organization, EURO Reports and Studies 1978, World Health Organisation, Copenhagen. 